\title{
Philosophical Study of Scientific Proof
}

\author{
Bondarenko Stanislav Borisovich \\ Kursk Filial at Plekhanov Russian University of Economics
}

\begin{abstract}
The scientific proof is the highest type of the rational proof. The mankind is looking for the best technology of the reasonable demonstration. What is a proof? What is a scientific proof? Philosophical investigations of proofs have the long history. Philosophy is exploring physics, mathematics, astronomy, biology, history, and so on. Science demands strict proofs. Science uses the specific methods as the optimum technologies for the achievement of the truth. Strictness of the proof depends on the aim algorithm: the distribution of the functions between parts of the proof. The beginning stage, the middle parts, and the ending stage are the unit of the proof. Philosophy can make the correct model of the scientific proof only! Science and its methodology develop and the growth of knowledge has not the finish. The rational ideals improve continually. Science is looking for the criterion of the demonstrative strictness. The adaptation algorithm of the scientific method is the best technology for the achievement of the truth.

Keywords: science, proof, model, method, unit, algorithm
\end{abstract}

\section{Introduction}

The problem of scientific proof is one of important and complex philosophical problems in science. Ancient philosopher Protagoras asserted that the proof is impossible. Protagoras propagated the debates. He called that personality need not agree with another opinions and people did not believe somebody. The problem of scientific proof requires new investigations and considerations. The development of modern philosophy is complicated reinforcing differentiation of science and the narrow scientific specialization; the rapid growth quantity of the scientists, the books, the journals, and the conferences; the existence of the diverse philosophical schools; the absence of the strict criterion for the estimate of philosophical knowledge; and the low level of philosophical education and intellect. The numerous special scientific communities found the autonomic organs of the self-management. The quality of the results controls the leading scientists as the competent experts. However, the collectivism of the expertise does not generate the constant investigations for the establishment of the common demonstrative laws and for the organization of the dialogue among all scientific societies. More than that some scientists deny a social usefulness of philosophy publicly and step out against the philosophy of the science and methodology. In condition of the reinforcing differentiation, the independence in the scientific knowledge is transformed in the self-sufficiency of communities. The closing special scientific communities generate the negative clan tendency in the organization of the science. The problem of the scientific proof will be investigated the big number of unlike scientists usefully. The history of sciences perfects and the modern society demands the new technologies of philosophical generalizations. The programs and the methods of

Stanislav Borisovich Bondarenko, Ph.D., professor, Department of Social and Humanitarian Sciences, Kursk Filial at Plekhanov Russian University of Economics, Russia; main research fields: Philosophy, History of Science, Sociology of Science and Education, Logic, and Cosmology. Email: bondsb@rambler.ru. 
education on the philosophical faculties are modernized; the international competitions and discussions are made regularly; and the education programs for the philosophy of the science get improved. The philosophical enlightenment is actual in the 21th century and the philosophical education is required with the development of the modern sciences. It is possible that UNESCO and International Federation of Philosophical Societies will establish the committees which will make the methodological codex of science.

The problem of proof was formulated when ancient philosophers explored epistemological distinctions between truth and mistake. Democritus did the classical logical analysis of the proposals and made the impotent inference that truthful and wrong knowledge existed. Ancient philosophers (Pythagoras, Thales, Anaximander, Anaksimen, Anaxagoras, Socrates, Plato) developed the productive philosophical ideas about the unity of the empirical and theoretical knowledge. Democritus constructed the fundamental conception of the science which rendered determinative influence on the development of European sciences. According to his theory, the science must join the facts solidly, which established and verified by experience with its heuristic causal explanations. The creation of great ancient scientist Archimedes employed the bright example of correct new methodology.

\section{Aim of Scientific Proof}

The author has offered the conception of scientific proof in contemporary scientism. The main principle in the scientific methodology asserts a truth and a lie, which are different. This principle has determined the requirement by the cognitive subject in indissoluble unity of the truth and the proof. The main aim of scientific investigation discovers the truth trustily. Methodological criterion of scientific truth is the proof. In science, the truth does not exist without the proof and the proof does not exist without the truth. Scientific communities affirm a truth only if knowledge has got methodological full proof publicly. Distortions, excisions, interpolations, and substitutes are not admitted in scientific text. The collective scientific reason requires the truth together with the uncovered proof. The philosophy of science explicates logic and linguistic rules for the construction of the proofs and the formulation of the correct assertions. Logical problems are explored by Aristotle. Scientific societies do not satisfy public declarations of some authorities or groups of scientists - "this is the truth" or "this is the proof." Scientists need the appropriate publication which contents the descriptions of the cognitive acts. Indicated procedure must be verified by the standard methods. The intuition and the surmises of the scientists indicate one of possible ways for the discovery of the truth and the construction of the scientific proof. History of science contents many negative instances which some opinions of the great investigators do not confirm in the process of scientific development. The reciprocal digit correspondence principle between the truth and the proof has been strengthened in methodology solidly.

\section{Self-Sufficiency of Scientific Proof}

The strictness of the proof depends on steady aspiration of scientific knowledge towards self-sufficiency, autonomy. This tendency has been given the combination of the causes. Firstly, science relates to unscientific knowledge critically and scientists do not admit other (mythological, religious, common, political, artful) means of the proof. Secondly, science works the specific investigative methods which one can overcome subjectivism, dogmatism, irrationalism, and nationalism. Thirdly, general feature of all scientific methods is demonstrative results. If the investigation does not satisfy standard methodological requires, it uses up the unscientific method. Fourthly, progressive science produces the professional communities of scientists which 
edit the journals and organize the conferences, the congresses, or the seminars. Fifthly, scientific truth services the fundamental for the rational convictions of politicians, businessmen, journalists, and socialness. Sixthly, science makes self-control and self-verifies the inferences strictly. Science is self-cleaned and self-estimated. Seventhly, it makes the search of the higher rational criterions in knowledge and conscious, the aspiration at the attainment of the limit in the perfection of the researches. Eighthly, science has transformed the specific type of knowledge. Scientific knowledge needs self-sufficiency but science does not need an extravagance. Science researches trusty model of the proof and scientists aspire to attain the limit of the perfection in the knowledge in order that community can guaranty higher quality of its results. The development of the contemporary scientism philosophy has admitted to reconstruct universal structural-functional pattern of scientific proof which is composed of solid nucleus of the scientific methodology and guaranties the unity of science, differentiation, and integration in science. The national and historical features in the organization of science (USA, Russia, Canada, France, Germany, Great Britain, Greece, Italy, Japan, China, India and so on) do not destroy the universal pattern of the scientific proof. All sciences use one common pattern of the scientific proof and fulfill the universal demands for the solution of the cognitive problems. Common pattern of the scientific proof does not prohibit to use the separate methodological rules in the concrete sciences.

Why has science got the universal pattern of the scientific proof? Methodology of scientific knowledge is developed towards the realization of the fundamental idea that the finished algorithm for the solution of the cognitive problems by standard productive methods exists. The proof is the process of mind and appropriate empirical acts from the dubiety to the acquaintance. The proof is the method of the separation for the hypotheses and the facts.

\section{Structural-functional Model of Scientific Proof}

Scientific proof has the structure and uses methodological criterions for the secretion of elements and parts. Each method of scientific proof has one beginning, final number of middle parts, and one ending. Demonstrative process is directed from the beginning to the final result. The problem is put in the beginning of proof. The phase of proof as a beginning fulfils impotent functions in construction of strict proof: expedient, significant, stimulant, analytical, regulative, controllable, organized, selective, valued, directive, determinative, prognostic, and explanatory. The ending of proof maintains results in the form of the correct asserts. The final phase of proof fulfils the specific functions: crowned, resultant, productive, pragmatic, conventional, modal, and interpretative. Because the process of scientific proof has one-directive and unturned character, main functions of middle parts are: estimation of the reciprocal digit correspondence between beginning and ending phases of proof, the elimination of contradictions and accidents, and the explication of necessary arguments and strict algorithm.

The productive result has the highest value for the scientific investigation. The process of proof keeps the consequent and logical non-contradictory chain of evident elements because all proofs are verified and reproduced. Number of demonstrative elements in algorithm must be final since the demonstrative process is managed. Main problem for the middle part of proof connects the beginning and the final phase of one proof in the functional and logical whole in order to except chances and contradictions. Number of parts aspirates to reduce to minimum since scientific communities need positive final result because parts of proof have certain functional destination. The increase number of parts can generate the involvement and inconsequence. One-directive proof is an opened unit of all phases and elements since the consequent does not change. The 
consequent of demonstrative elements is determined the aim and method. The calculation of elements may be voluntary. The conceptions of part or element in the structure of proof are defined the community necessarily in order to count the parts and the elements exactly. Since the scientific communities use the standard methodological requests and the methods for the formalizations of proofs, they need know all parts, elements and, its connections. Each part of proof must be functional certain and has the place in the system organization of proof. Main role in the selection of the demonstrative elements fulfils the common pattern of the demonstrative methods which is criterion for the identification elements and structure of the proof.

Ancient philosopher Agrippas asserted that each proof and each element of proof are divided infinitely. However, infinite number of elements in the proof exhibit nonsense, untrustworthiness, and doubtfulness. Cognitive subject manages the process of proof by means of the common demonstrative pattern. The divisibility of each part may be different. Because methodology demands except structural-functional divisibility of parts which destine for the construction of proof with the beginning phase, search of the best element combination for scientific proof is creative process requesting professional art. Ancient philosopher Pyrronas formulated very complex argument: All proofs are relative and untrustworthiness; absolute proof does not exist; absolute criterion of trustworthiness for proof is nothing. Analysis of this argument request defines functions of proof model and relativity concept of proof. Main function of proof model is criterion of existence for proof: to exist or not to exist. Model of proof estimates authenticity of fact that demonstrativeness is fulfiled or realized. Model of scientific proof must solve fundamental philosophical questions: "Does the proof exist?" and "What significance has the proof?" The relativity of each proof does not mean that existence of proof depends on point of view or outlook of cognitive subject. Relativity and approximation of proof is acknowledged in methodology of science but the proof is not a myth or a speculation. Science has revealed its cognitive power generating absolute and relative truths. Scientific proofs are based on historical-limited knowledge. Each method of investigation realizes common pattern of proof.

\section{Conclusion}

Absolute ideal perfect model of proof does not exist and this model will never be created since cognitive subject develops and enriches new scientific knowledge. Limit of perfection does not exist in science, methodology, experience, or manipulation of mass conscience. New knowledge is born in development, old knowledge is enriched and completed new knowledge. System of requests to the proof becomes compound and refined. Methods of proof are concretized in different domains of the science. Main universal requests to the proof do not revise and do not substitute other requests. Main requests to scientific proof are conserved. System of main requests is the carcass for standard methodological model of scientific proof. This model is the base of belief in final results.

Main requests to scientific proof compose the aggregate: application of scientific conceptions, adequacy of two-meaning formal logic, reception of results with specific methods, unit of empirical and theoretical means, experimental model, structural-functional whole, positive rating of results in professional scientific communities, and so on. Strictness of proof has confirmed adequate realization of standard demonstrative patterns in whole fragment of scientific knowledge. Publicity, openness, fullness, short, professionalism, completeness, coherence, and identity are necessary condition in order to reproduce and verify the proof. New generation of scientists for continuation of scientific investigation must verify all proofs many times. The trustiness of verification justifies the strictness of demonstrative power of scientific methods. 
Existence of many ways for achievement of aim but one proof contains single way for achievement of its aim. If one aim of proof has achieved by two ways consequently, two ways of proof exist. Important value has reciprocal independent methods of proof. If scientific communities use a lot of reciprocal independent methods of investigation which gives typical results, problematic situation is resolved in form of collective inferences. Each method of investigation is founded on universal model of proof because methodology does not prohibit to use results receiving different methods. Development of methodology does not stop since a limit of perfection for process of proofs does not exist. The contemporary scientistic model of proof is modern philosophical generalization of demonstrative patterns in scientific knowledge.

\section{Works Cited}

Aristotle. The Works of Aristotle, Vol. 1. Oxford: Clarenden Press, 1928.

Bachelard, Gaston. The New Scientific Spirit. Paris: PUF, 1949.

Bacon, Francis. A Critical Edition of the Major Works. Ed. Brian Vickers. Oxford and NY: Oxford University Press, 2000.

Gerber, William. The Domain of Reality. NY: King’s Crown Press, 1946.

Descartes, Rene. Discourse on Method and Related Writtings. London: Pengiun, 1999.

Kant, Immanuel. Critique of Pure Reason. Cambridge: Cambridge University Press, 1998.

---. Lectures on Logic. Cambridge: Cambridge University Press, 1992.

Leibniz, Gottfried. Philosophical Essays. Indianapolis: Hackett, 1989.

---. Philosophical Papers and Letters. 2nd ed. Dordrect: D. Reidel, 1969.

Mill, John Stuart. System of Logic/Collected Works of John Stuart Mill. Toronto: University of Toronto Press, 1963.

Nagel, Ernest. The Structure of Science. NY: Routledge and Kegan Paul, 1961.

Russel, Bertrand. Logic and Knowledge: Essays, 1901-1950. London and NY: The Macmillan Company, 1956.

---. Essays in Analysis. London: G. Allen and Unwin, 1973. 